\title{
Fibroid originated from rudimentary horn in mullerian agenesis
}

\author{
Deepika*, Smita Gupta, Leena Wadhwa, Lata singh
}

Department of Obstetrics and Gynecology, ESI PGIMSR Basaidarapur, New Delhi, India

Received: 27 June 2017

Accepted: 25 July 2017

\section{*Correspondence:}

Dr. Deepika,

E-mail: 1hmcdeepika@gmail.com

Copyright: () the author(s), publisher and licensee Medip Academy. This is an open-access article distributed under the terms of the Creative Commons Attribution Non-Commercial License, which permits unrestricted non-commercial use, distribution, and reproduction in any medium, provided the original work is properly cited.

\begin{abstract}
Mullerian agenesis or Mayer Rokitansky- Kuster- Hauser syndrome is defined by congenital absence of both the uterus and vagina. It affects 1 in 4000-5000 females. Leiomyoma arising from the uterine remanent in case of MRKH is very rare. Very few cases have been reported in literature. The exact etiopathogenesis of leiomyoma from the rudimentary uterus in MRKH syndrome is not known. We are reporting a rare case of 35-year-old married, nulliparous female who presented with primary amenorrhea and lump in lower abdomen since, 1 year. On physical examination, a mass of 18-week size of uterus, firm in consistency, irregular, nontender, mobile from side to side, occupying right iliac and hypogastric region was detected. Provisional diagnosis of multiple leiomyoma with mullerian anomaly was made on USG and MRI for which laparotomy was performed. Per-operatively, there was a mass of approx. $15 \times 8 \times 8 \mathrm{~cm}$ consisting of multiple fibroids present, uterus not visualized separately. Right ovary and tube absent. Left fallopian tube and ovary were normal arising from left rudimentary horn with no endometrial tissue. Blind end with no cervix. Partial agenesis of vagina. No communication possible between rudimentary horn and vagina. Patient underwent hysterectomy in view of non-functioning uterus. Histopathology report confirmed the diagnosis. Finally, it was diagnosed as a case of multiple leiomyoma originating from uterine remanent. Postoperative period was uneventful.
\end{abstract}

Keywords: Agenesis, Histopathology, Mulleriananamoly, Post-operative period

\section{INTRODUCTION}

Mullerian agenesis or Mayer Rokitansky- Kuster-Hauser syndrome is defined by congenital absence of both the uterus and vagina. It affects 1 in 4000-5000 females. Leiomyoma arising from the uterine remanent in case of MRKH is very rare. Very few cases have been reported in literature. The exact etiopathogenesis of leiomyoma from the rudimentary uterus in MRKH syndrome is not known.

\section{CASE REPORT}

35-year-old married nullipara female presented with primary amenorrhea and lump in lower abdomen. She noticed a lump There was no history of cyclical abdominal pain, dyspareunia or hormone withdrawal bleeding. She had normal appetite and no history of weight loss. She did not have the bladder or the bowel complaints. She neither had excessive growth of body hair nor a change in her voice. No history of galactorrhea. On general physical examination, she had a female body contour and normal hair pattern. Her height was $154 \mathrm{~cm}$ and weight $55 \mathrm{~kg}$. Thyroid was not enlarged. breast examination-tanner stage 3. Pubic hair /axillary hairtanner stage 4. No inguinal lymphadenopathy. Per abdomen examination- a mass of 18-week firm to hard mass, irregular, nontender, occupying right iliac and hypogastric region, mobile from side to side. There was no free fluid in the abdomen. She did not have 
hepatosplenomegaly. on local examination, External genitalia normal. P/s- two-centimeter vagina dimpling present cervix not visualized, thick septum present. Per vaginum examination- a short vagina with a? uterus firm mass of size 18 week, nontender, mobile and bilateral fornices free. Findings confirmed on per rectal examination.

Investigation: Blood investigation and karyotyping was normal. Usg pelvis-A large well defined heterogeneously hypoechoic lesion in right adenexa with lobuated appearance measuring $11 \times 7.5 \times 11 \mathrm{~cm}$. The lesion noted abutting cervical region. Cervix appears thinned out, uterus could not visualize separately. Right ovary appears normal. Left ovary could not visualized. MRI Pelvis: Uterus is enlarged in size $(13 \times 6 \times 8.6 \mathrm{~cm})$ and shows multiple well defined intramural lesion of varying size $12 \times 7 \times 8 \mathrm{~cm}$ in the anterior wall as well as fundal area of uterus displacing the endometrium posteriorly Figure 1.

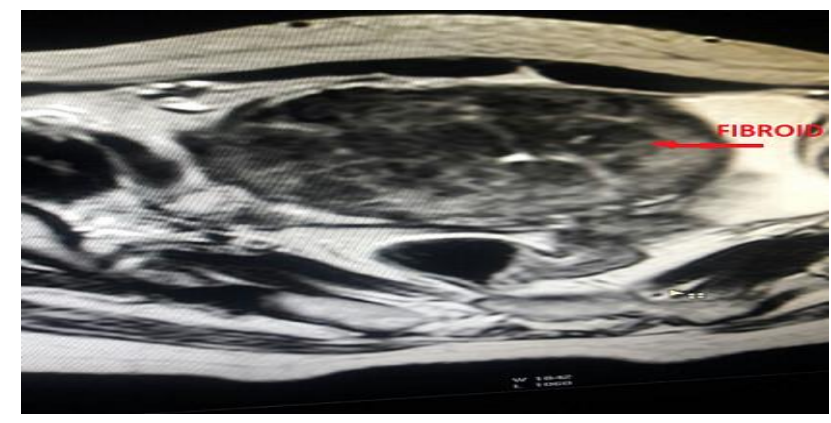

Figure: 1 MRI Pelvis-multiple well defined intramural lesion of varying size.

The lesion is isointense on T1 weighted and hypointense on T2W. Cervix is hypoplastic.? Fibroid or mullerian agenisis. The provisional diagnosis of fibroid uterus with mullerian anamoly made. Patient counselled and Plan for laparotomy with myomectomy/hyserctomy made. Per op findings: uterus size 18-20 week, uterus bicornuate with left sided rudimentary horn and right sided horn with multiple fibroids present. Both horn was noncommunicating Figure 2.

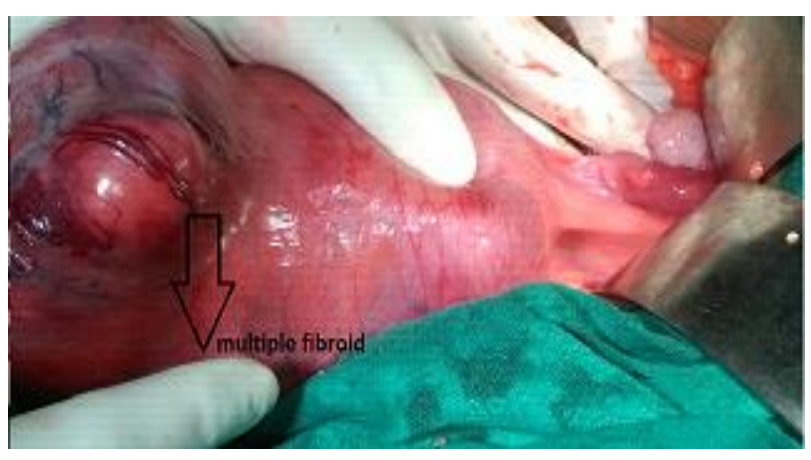

Figure 2: Mass of aprox. $15 \times 8 \times 8 \mathrm{~cm}$ consisting of multiple fibroids present, uterus not visualized separately. No communication between the lower part of the mass and vagina seen.
Both side cevix absent with partial agenesis of vagina. Right sided horn fibroid of size 6" 65 " inch size removed.no endometrial cavity. On left side? underdeveloped round ligament.no communication could be possible between uterus and transverse vaginal septum Figure 3.

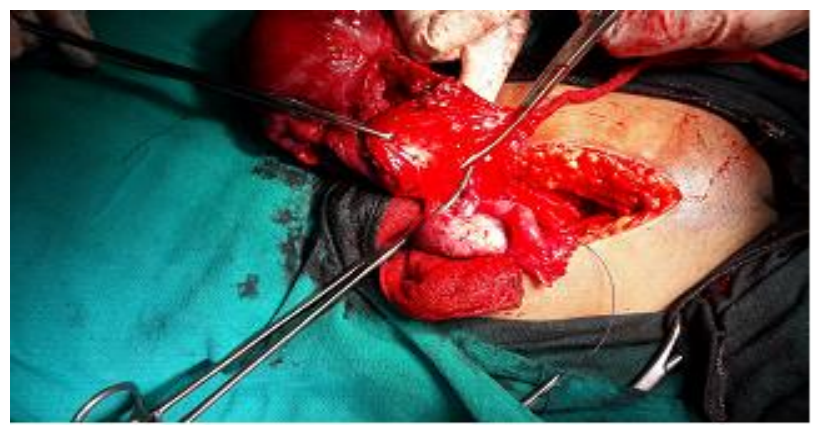

Figure 3: Lower part of fibroid enucleated, rudimentary horn seen along with left tube and ovary.

A total abdominal hysterectomy was performed in view of the presence of large leiomyomas in a non-functional. Post-operative period was uneventful. On cut section of the specimen, uterine horns were found noncommunicating, and they did not have endometrial lining. Both the leiomyomas had whorled appearance (Figure 4) and they did not show features of degeneration. Histological examination revealed features of leiomyoma with a hypoplastic bicormate uterus.

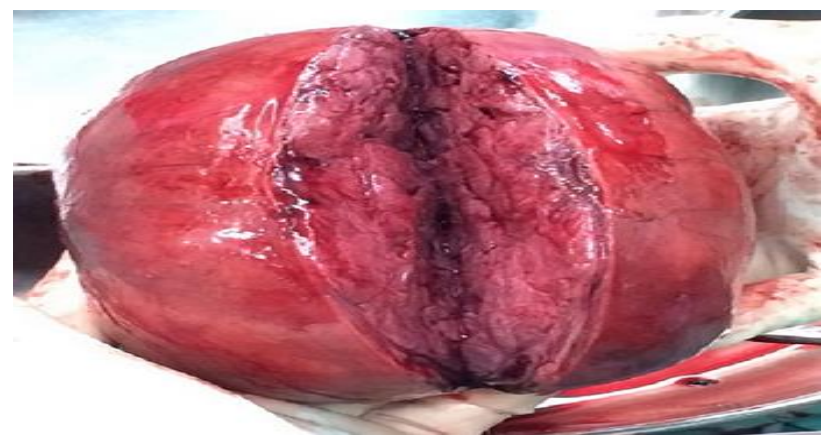

Figure 4: Cut section of the specimen: whorled appearance and they did not show features of degeneration.

\section{DISCUSSION}

Mullerian agenesis or Mayer Rokitansky- Kuster- Hauser syndrome is defined by congenital absence of both the uterus and vagina. It is cause of primary amenorrhea in $15 \%$ of women. ${ }^{1}$ It is considered in a class I Mullerian duct anomaly and it has been subdivided into two types typical (type A) and atypical (type B). Patients with type A syndrome have normal fallopian tubes because of symmetrical buds. Patients with type B have asymmetric muscular buds (aplasia of one or both buds or, when both buds were found, one bud was smaller than the other one). Different types of congenital anomalies like renal 
agenesis, syndactyly and cardiac defects are assosciated with atypical type. ${ }^{2}$ Other anomalies include skeletal anamolies are also assosciated with MRKHS. Klippel Feil syndrome, characterized by congenital fusion of cervical spine, short neck, a low posterior hair line and limited range of motion in cervical spine may coexist with MRKHS. ${ }^{3}$ Approximately $15-36 \%$ of women with uterine agenesis also have defects in the urinary system and $12 \%$ have scoliosis. Recently a syndrome has been described with Mullerian agenesis known as MURCS (mullerian duct aplasia, renal aplasia, cervicothoracic somite dysplasia) has been described recently. ${ }^{4}$ In mullerian agenesis, as ovarian function is normal. So, estrogen dependent pathological conditions can develop in mullerian anamolies like myomas and endometriosis, that had happened in our case.

Leiomyomas of uterus are estrogen dependent tumours which originate from smooth muscle cells of normal uterus. The etiopathogenesis of leiomyomas are assosciated with genetic predisposition, hormones and few growth factors. However, the exact etiopathogenesis of leiomyoma from the rudimentary uterus in MRKH syndrome is not known. Non-communicating uterine horns of unicornuate uterus has also been reported to have myomas. ${ }^{5}$

Mullerian ducts have smooth muscle cells at their proximal ends, which probably may give rise to the growth of leiomyoma from the rudimentary uterus in MRKH syndrome. ${ }^{6}$ In imaging techniques, Threedimensional (3D) ultrasound is a new imaging technique, more accurate than two-dimensional ultrasound and equal or better than MRI at assessing mullerian anamolies. CT and MRI are very useful in the diagnosis of MRKH syndrome with leiomyoma and in providing road-map for surgery, latter being very sensitive and specific. ${ }^{2}$ On computed tomography (CT), leiomyomas are well circumscribed masses iso-to hypodense to myometrium and show variable enhancement patterns. Laparotomy/laparoscopy is indicated when a pelvic mass is detected in a case of Mullerian agenesis. The removal of the symptomatic tumor with the adjacent uterine remnant is indicated which can be done laparoscopically.,8

\section{CONCLUSION}

Rudimentary uterine horns, irrespective of whether they exist in association with a patent uterovaginal tract or in isolation, should be removed. Patient presenting with primary amenorrhoea/known mullerian anomaly with lump abdomen should be suspected for leiomyoma. The assisted reproductive techniques and maternal surrogacy enable a woman without a uterus to have her own genetic children. Uterine transplantation can be thought of in near future.

\section{Funding: No funding sources \\ Conflict of interest: None declared \\ Ethical approval: Not required}

\section{REFERENCES}

1. Welt CK, Barbieri RL. Etiology, diagnosis, and treatment of primary amenorrhea. Upto Date [updated Apr 14, 2009].[Links]. 2007.

2. Rawat KS, Buxi TBS, Yadav A, Ghuman SS, Large SD. Leiomyoma in a woman with MRKH syndrome. J Radiol Case Rep. 2013;7(3):39-46.

3. Nirmala Duhan, Yogender S Kadian, Urmila Duhan, Nidhi Rajotia. Mullerian, Renal and Skeletal Anomalies A Rare Association. JK Sci. 2009;11(2).

4. Willimsen WN. Combination of the MayerRokitansky-kuster and Klippel Fiel Syndrome-a case reportand literature review.Eur J Obstet Gynecol Rerod Biol. 1982;13:229-35.

5. Lico D, Morelli M, Venturella R, Mocciaro R, Di Cello A, Rania E, Zullo F. An Unusual Extremely Distant Non-Communicating Uterine Horn with Myoma and Adenomyosis Treated with Laparoscopic Hemy-Hysterectomy. J Minimally Invasive Gynecol. 2013;20(6):S187.

6. Kallol K Roy, Suman Lal, Neelam Banerjee Large leiomyomas in Mayer-Rokitansky-KüsterHauser syndrome. J Obstet Gynecol India. 2005;55(2):1834 .

7. Singh S, Chakravarty B, Chakravarty M, Chakravarty A. Large Fibroid arising from Mullerian Remnant Mimicking as Ovarian Neoplasm in a Woman with MRKH Syndrome. Int J Infert Fetal Medic. 2012;3(1):30-2.

8. Lanowska M, Favero G, Schneider A, Kohler C Laparoscopy for differential diagnosis of a pelvic mass in a patient with Mayer-Rokitanski-KüsterHauser (MRKH) syndrome. Fertil Steril. 2009;91(3):931.e17-8.

Cite this article as: Deepika, Gupta S, Wadhwa L, Singh L. Fibroid originated from rudimentary horn in mullerian agenesis. Int J Reprod Contracept Obstet Gynecol 2017;6:4147-9. 